\title{
POSTALES DE ESPAÑA ${ }^{1}$
}

Estrella de Diego

Universidad Complutense de Madrid

\begin{abstract}
RESUMEN
La construcción de "lo español" como fenómeno cultural ha impregnado toda la historia de la producción visual en nuestro país. Desde la alta cultura a la baja cultura, el mismo tipo de representaciones ha ido proliferando a lo largo del siglo XX, sin presentar grandes cambios, en el fondo, durante los diferentes regímenes políticos. Partiendo de esa imagen "pintoresca" de España descrita por los viajeros del XIX, el artículo propone un recorrido por las Visiones de España de Sorolla y los carteles oficiales de turismo, mostrando algunas afinidades que hacen pensar en unos códigos compartidos que no hablan de la "realidad", sino que la crean.
\end{abstract}

Palabras clave: contrucciones culturales, "lo español", cultura visual, carteles de turismo, turismo, Sorolla

ABSTRACT

The construction of "Spanishness" as cultural phenomenon has been quite relevant for the history of visual production in Spain. From high culture to low culture the same modes of visual representations have proliferated during the $20^{\text {th }}$ century, without relevant changes occuring from one political regime to another. Taking this "picturesque" described by $19^{\text {th }}$ century travellers image of Spain as a starting point, the article focuses on Sorolla's Visiones de España and the official touristic posters, revealing many affinities that point to shared codes which do not so much speak of "reality" as create it.

Keywords: cultural constructions, Spanishness, visual culture, tourism posters, tourism, Sorolla

\section{Picasso: pintor "español"}

Cuando Pablo Picasso y Gertrude Stein se tropiezan casi por casualidad en París durante los primeros años del siglo $X X$, se produce un acontecimiento cuya trascendencia entonces tal vez ni siquiera ellos llegan a adivinar. Picasso ve a esa mujer luminosa y fuerte y se queda prendado de su aspecto inusual: quiere pintarla. Por su parte Stein se fascina por Picasso, revestido de la extraordinaria vitalidad que debía desplegar entonces.

Ese principio de una de las amistades más ardientes de los inicios de la modernidad no tarda en dar sus frutos - y no me refiero sólo a la calurosa y fiel defensa que Stein hizo del "cubismo" a lo largo de su vida. Poco después de conocerla, en 1906, Picasso lleva a cabo el popular retrato conservado en el Museo Metropolitano de Nueva York: una Stein máscara a la cual termina por pintar recomponiendo el rostro en la memoria, como suele hacerse con las civilizaciones extinguidas, pese a haber posado la amiga durante un centenar de sesiones.

Por su parte la escritora americana piensa en la manera de corresponder a tan especial regalo y apenas tres años después publica el primero en una serie de textos dedicados al amigo pintor. El primer "Picasso" aparecía entre las páginas de Camera Work en 1912, seguido de "If I Told Him: A Complete Portrait of Picasso" escrito en 1923, un curioso retrato poemado. Sin embargo, es en 1938, siendo ambos personajes consagrados en la escena internacional, cuando aparece el texto más extenso y más completo. Ese "Picasso" es casi una suerte de ajuste de cuentas con el "cubismo" y, de alguna manera, hasta una biografía sentimental del malagueño. 
La gran escritora, la americana de las frases fragmentadas y la literatura de montajes y fracturas, entendía como nadie muchas de las puestas en escena del amigo. Fue ella quien lanzó, en el mencionado texto, la tesis del Picasso "primitivista" - primero máscaras negras y luego íberas - cuyo interés sigue vigente incluso tantos años después de aparecida la obra, en primer lugar porque a partir de dicha tesis se construye uno de los aspectos más populares del "mito Picasso".

Pero, ¿quién era Picasso, a quién veía Stein en Picasso? Es más: ¿a quién describía en realidad en el texto de 1938? La pregunta se contesta con la propia lectura del texto. Aparte de los lugares comunes -el Picasso chamán en su rescate del arte de "los otros"-, lo que podría interesar más en este contexto es la mirada desde la cual Stein se aproxima al Picasso "español" particular que había apuntado Apollinaire en Los pintores cubistas como parte de la innovación picassiana:

El malagueño nos hería como un frío breve. Venía de lejos, de las riquezas de composición y de decoración brutal de los españoles del siglo XVIR.

Stein moldea y apostilla esa tesis en su juego de formulaciones sobre los "otros" y presenta a un Picasso "español", con "carácter español". Y a un Picasso "oriental", ya que España y Rusia para Stein, como para el resto de la tradición europea de los países hegemónicos, acaban por conformar el borde, el vértigo, los límites "exóticos" del continente. De hecho, es probable que la fascinación que ambos países ejercen sobre el resto de Europa a lo largo del siglo XIX y primeros del $X X$, se deba a su posición geográfica, aquella que ha condicionado una historia muy contaminada de las culturas del otro lado, causa determinante en esa percepción.

Tanto en el caso de España como en el de Rusia, los intelectuales europeos, en su invención de la "comunidad", entendido el término al modo de Anderson, iban buscando un locus de la nostalgia. En el caso de España, del legendario mundo árabe - "sarraceno", dice Stein ${ }^{3}$; en el de Rusia, del bizantino. Se trata, pues, no sólo de algo que podría denominarse la "nostalgia de Oriente" -lo "exótico" en términos espaciales-, sino de la nostalgia de un "pasado orientalizante" ya muy diluido, muy polucionado. Dicho de otro modo, lo "exótico" en términos temporales, la exasperación de lo "exótico": lo extinguido, lo que no va a volver a ser.

España y Rusia acaban siendo lo "otro", portadoras de una memoria que, pese a ser compartida en muchos aspectos por el resto de Europa, resulta extraña. El propio André Breton, padre del surrealismo, comenta en una conferencia dictada en 1922 con motivo de una visita a Barcelona a propósito de las mujeres que va encontrando:

(...) y mi perfecta ignorancia de la cultura española, del deseo español, una iglesia en construcción que no me disgusta si olvido que es una iglesia, su clima, las mujeres con las que me cruzo en la calle, esas mujeres que me son deliciosamente extrañas, desconciertan un poco mi audacia ${ }^{4}$.

En términos bastante similares se organizan las descripciones estereotipadas de tantos viajeros por nuestro país, desde tiempo inmemorial cuna de las mujeres más apasionadas en las invenciones foráneas. Así presenta, por ejemplo, a las andaluzas Edmondo de Amicis en su diario de viaje por España, Spagna. Diario di viaggio di un turista scrittore. El suyo es un retrato repetido que podría haber escrito casi cualquiera, aquel que invoca una imagen manida de bandoleros y Cármenes a medio camino entre seducción y pecado o, mejor aún, entre placer y transgresión. O las dos cosas a la vez, como corresponde a un país católico contado por un escritor conservador:

No creo que en ningún país existan mujeres más capaces que las andaluzas para inducir a ser raptadas. No sólo porque despiertan la pasión que hace cometer tonterías, sino porque de verdad parecen estar hechas a medida para ser tomadas, recorridas y escondidas, tan pequeñas son y tan ligeras, rellenitas, flexibles, dulcísimas. Sus piececitos cabrían fácilmente los dos en un 


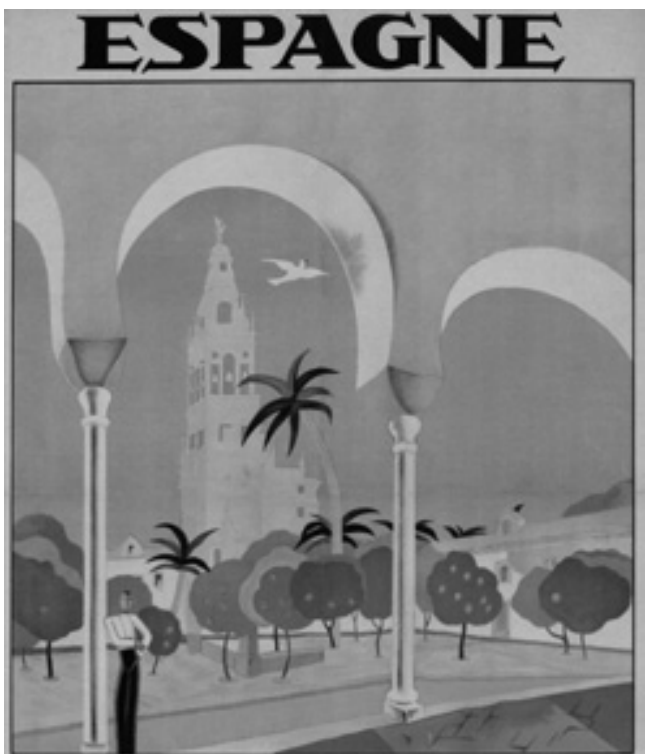

\section{LE CONFORT DE L'EUROPE LA LUXURIANCE DE LAFRIQUE VOUS ATTENDENT EN ESPAGNE}

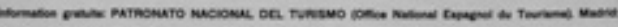

Fig. 1. Tejada, Espagne, Cartel, Patronato Nacional de Turismo, 1929. Fondos del Instituto de Estudios Turísticos del Ministerio de Economía y Hacienda.

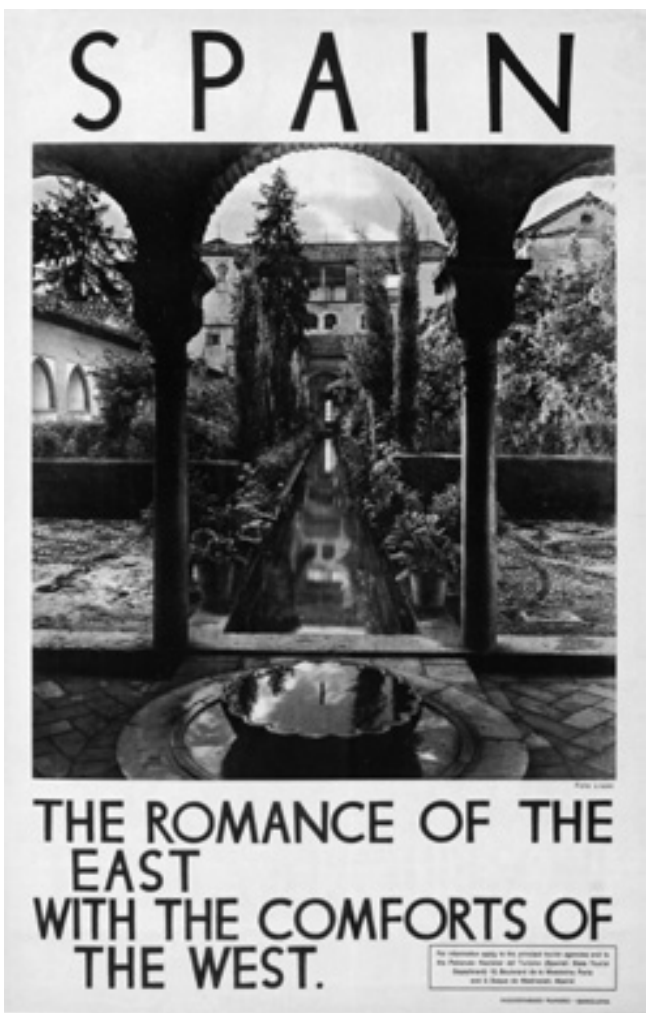

Fig. 2. Lladó, Spain, Cartel, Patronato Nacional de Turismo, 1930. Fondos del Instituto de Estudios Turísticos del Ministerio de Economía y Hacienda.

cia de un sueño manufacturado de diferencia que Europa buscaba en sus bordes o, dicho de otro modo, en sus fronteras: en las periferias. De hecho, si es cierto que España tenía una apariencia "africana", como repite entre otros Gautier en su Viaje por España, no lo es menos que no llegaba a ser tan "primitiva" como los países del Norte de Africa.

Sea como fuere, sería más preciso decir que casi no llegaba a serlo, a juzgar por las descripciones a menudo despiadadas de los visitantes, quienes se quejaban con frecuencia de las bárbaras costumbres españolas 0 , al menos, extraordinariamente peculiares desde el punto de vista del extranjero que llegaba hasta tierras sureñas. En su célebre libro aparecido a mediados de los 40 


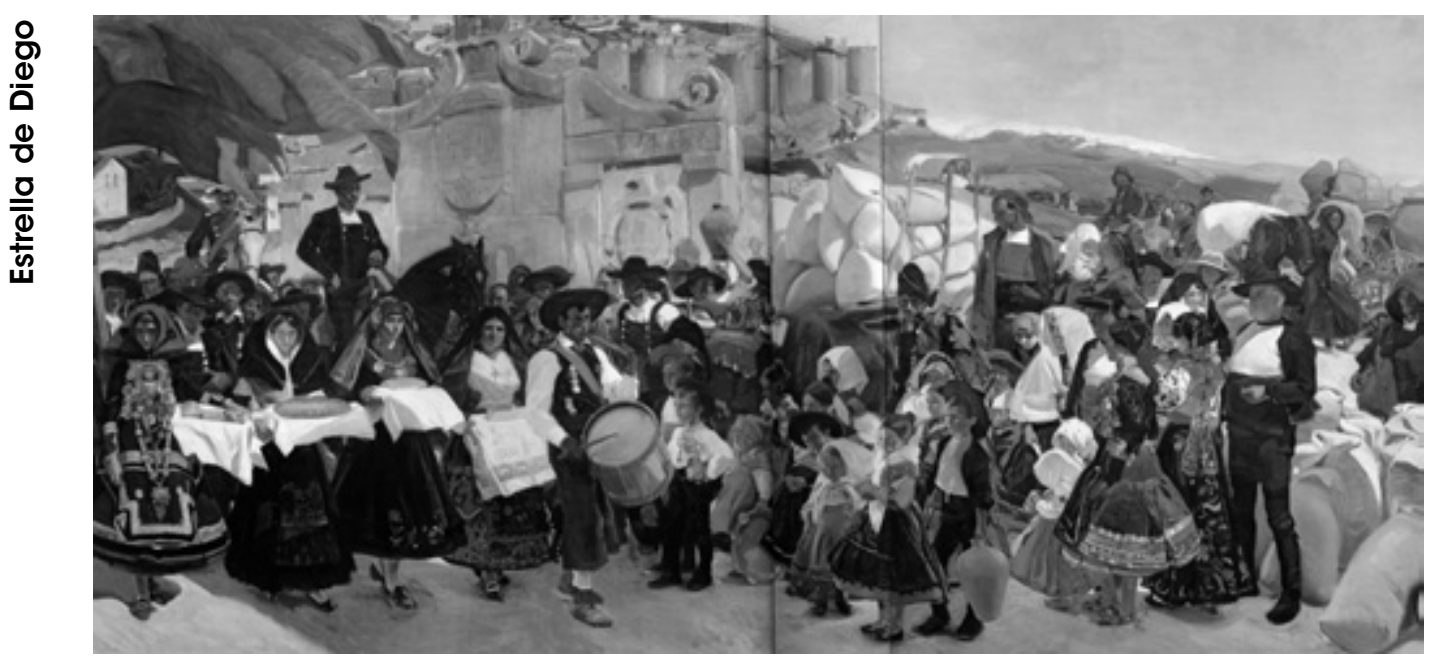

Fig. 3. Joaquín Sorolla, La fiesta del pan, Visiones de España, 1913.

del 1800, De París a Cádiz, apoteosis del tópico "españolista", Dumas comentaba al final de la carta escrita en su primer día en Córdoba:

Pospongo para mi próxima carta el relato de este viaje que, como verá, deja chicos a los viajes del capitán Cook, Mungo Park y Tamiser ${ }^{6}$.

Se podría, de este modo, ir más allá. El término "orientalismo" —que invoca o reúne realidades tan dispares y hasta disparatadas como "España" y "Rusia" - es un lugar de lo ambiguo, aquel que, según ha notado Said en su libro clásico, Orientalismo ${ }^{7}$, desvela la formulación binaria sobre la cual se construye el sistema de representación, denominación y dominación en Occidente. De hecho, en ese perverso juego de categorías estancas que conlleva el término "orientalismo" está implícita la idea que desvela una de las operaciones higiénicas que tanto gustan a Occidente: limitarse a mirar la escena desde fuera.

Queda claro en la llamada "pintura orientalista" donde el pintor se limita a mirar desde fuera la escena y a sus habitantes, en su mayo- ría mujeres que se representan apartadas de la realidad, casi atrapadas en una vitrina etnográfi$\mathrm{ca}$, como apunta Nochlin. Son, pues, las fantasías que constituyen un mundo aparte, museado, que jamás podrá contaminarnos y que simboli$z a$, sin duda, un discurso de autoridad donde se resumen también muchos de los más terribles estereotipos de género asentados en la cultura occidental.

Se sueña, así, lo que desde Occidente se imagina como "Oriente": esencialmente distinto o, en palabras de Lou Andreas-Salomé, un lugar de

culturas acabadas, como obras maravillosas, esquivas a la inaccesibilidad y fantástica sabiduría de antiquísimas tradiciones, en las cuales todos, quien quiera que sea, han nacido ${ }^{8}$.

Podría, pues, decirse que la fascinación de Rusia - quizás como la de España- deriva en primer lugar de su condición de territorio fronterizo, ése al cual apela la propia Lou AndreasSalomé al hablar de la tierra rusa y su diferencia con el otro Oriente. 


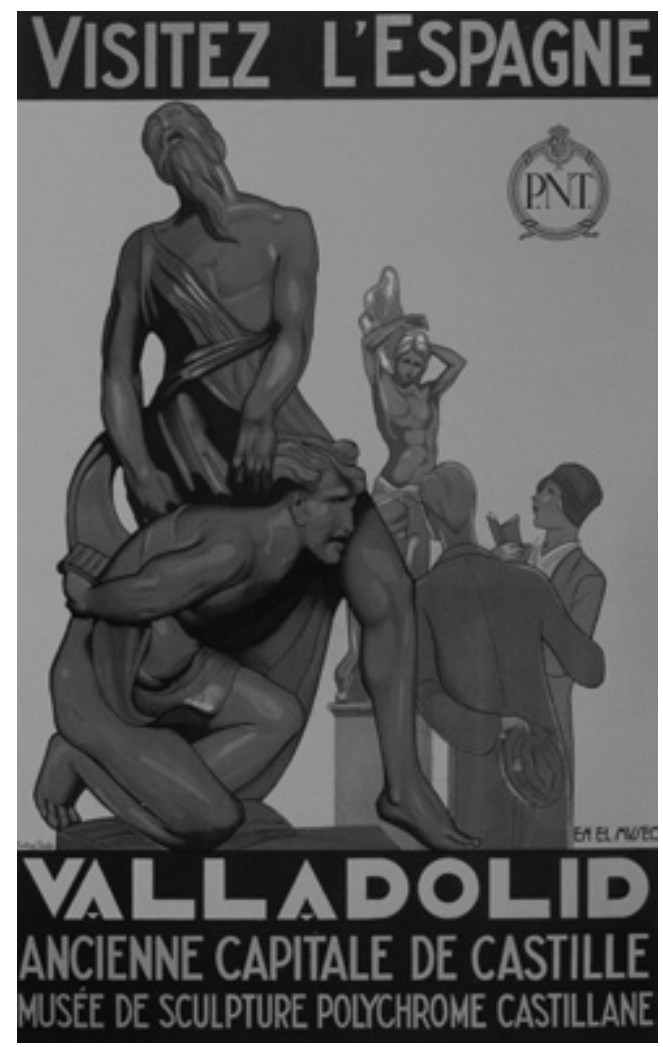

Fig. 4. Santonja Rosales, Visitez l'Espagne, Cartel, Patronato Nacional del Turismo 1929. Fondos del Instituto de Estudios Turísticos del Ministerio de Economía y Hacienda.

No obstante, incluso partiendo Stein de las ideas arraigadas sobre la España "exótica", presentes en los viajeros románticos y supervivientes incluso en la España de barrio chino y bailaoras de Bataille, Picabia o Man Ray, nociones de "exotismo" que llegan incluso desde España a las promociones turísticas de finales de los años 30 del XX —donde se publicitan los grandes monumentos árabes aludiendo a Oriente y hasta a Africa (Figs. 1 y 2) -, la escritora americana se apresura a aclarar cómo ese "orientalismo" al cual hace referencia no es "exótico sino (...) profundo, totalmente asimilado" .

Pese a todo, Stein está retomando el mito de lo "exótico próximo", el mismo que conlleva

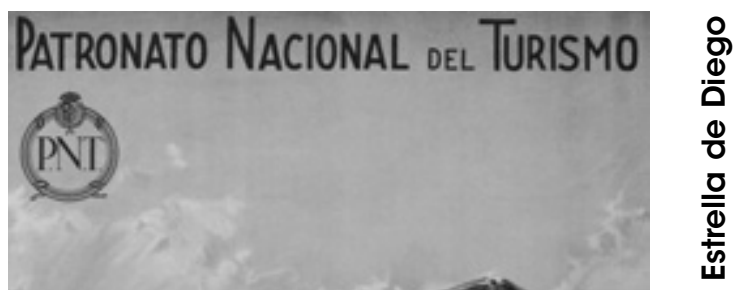

la imagen de lo "español". Pero ¿cuál era, en el fondo, ese "carácter español" para Stein? ¿Era tan diferente de las otras representaciones en boga que perviven a lo largo del siglo XX, como se hacía notar, a través de los carteles turísticos?

Seguramente no. También para Stein vuelve a tener algo de "primitivo", de salvaje, próximo a cierta desinhibición americana. Mientras que otros países de Europa seguían viviendo "en el siglo XIX, España por su falta de organización y América por su exceso de organización eran los fundadores naturales del siglo XX"10, comenta. Y no sólo. En ese típico juego de extrapolaciones que acaban por ver a los habitantes de lo "exótico" asimilados a sus paisajes, España terminaba 
por ser cubista: para Stein la realidad copiaba a las obras de Picasso. Es la idea de meter en un mismo saco a las ciudades, los paisajes y los habitantes que vuelven a explotar las mismas campañas publicitarias sobre la imagen de España.

Es éste, quizás, el punto más excitante de la aproximación de la escritora americana leída después de la revisión de Edward Said sobre el término "orientalismo". Si en todas y cada una de las apropiaciones indebidas "Oriente" es sólo una construcción cultural, ¿hasta qué punto no se basó la fascinación que despertaba Picasso entre muchos de sus contemporáneos en su "españolidad", en su "orientalismo"?

Más aún: ¿hasta qué punto no fue el mito heredero de muchas de las construcciones culturales en torno a "lo español" cultivadas por artistas anteriores, incluso del XIX y primeros del XX? ¿No se halla "lo español" atrapado en una puesta en escena que creíamos que nos pintaba tal y como éramos si bien, en el fondo, estaba sólo representando lo que se esperaba de nuestra imagen desde fuera, en otro sitio, lejos de casa?

\section{II. "Lo español" de Sorolla}

Desde las pinturas de los últimos años del XIX, conocidas bajo el apelativo "regionalismo" y de cuya moda participan los paneles decorativos Visiones de España en la Hispanic Society of America de Joaquín Sorolla" —encargados por Huntington y "tipificación" de las diferentes características de lo "español" en sus distintas regiones - hasta las campañas promocionales de turismo en plenos años 60 , el catálogo completo de imágenes que se conforma - y se asemeja- es parte de la citada ficción sobre "lo español". Se trata, además, de una ficción entendida desde varios otros puntos de vista: en primer lugar, ficción como collage, como "phantasy city", siguiendo el término propuesto por John Hannigan ${ }^{12}$.

De hecho, si se toma como punto de partida uno de los más impresionantes paneles de la serie de Sorolla, la que representa las dos Castillas y León, La fiesta del pan de 1913, lo primero que llama la atención es la capacidad del artista para dar coherencia a partes separadas y hasta independientes — desde la Sierra de Gua-

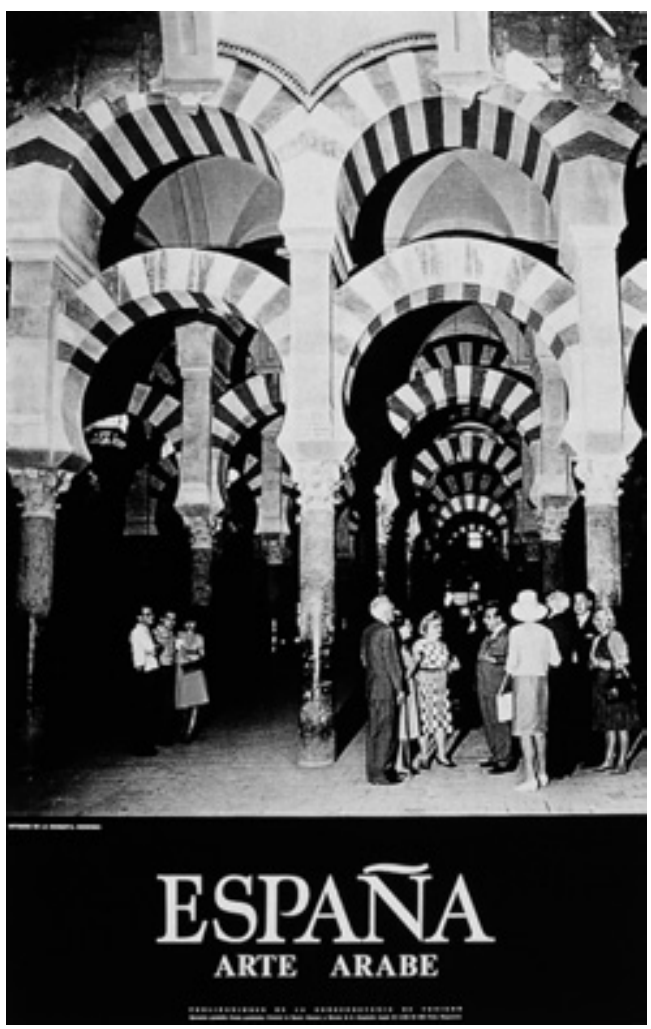

Fig. 6. Josip Ciganivic, España Arte árabe, Cartel, Ministerio de Información y Turismo, 1966. Fondos del Instituto de Estudios Turísticos del Ministerio de Economía y Hacienda.

darrama que coloca en medio, las montañas que separan ambas Castillas y que en el lienzo no aparentan los cien kilómetros que existen en la realidad, hasta los diferentes trajes regionales o cerámicas que representa como parte del mismo cortejo.

Se trata además, y otra vez por cierto, de una asimilación entre paisajes, ciudades, habitantes como parte de la construcción del estereotipo que se repite a lo largo de todo el repertorio iconográfico en la representación de "lo español". Pues si es verdad que Sorolla viaja mucho y copia del natural todos esos apuntes que junto con las fotografías - y hasta las postales - le ayudan a dar credibilidad a su tra- 


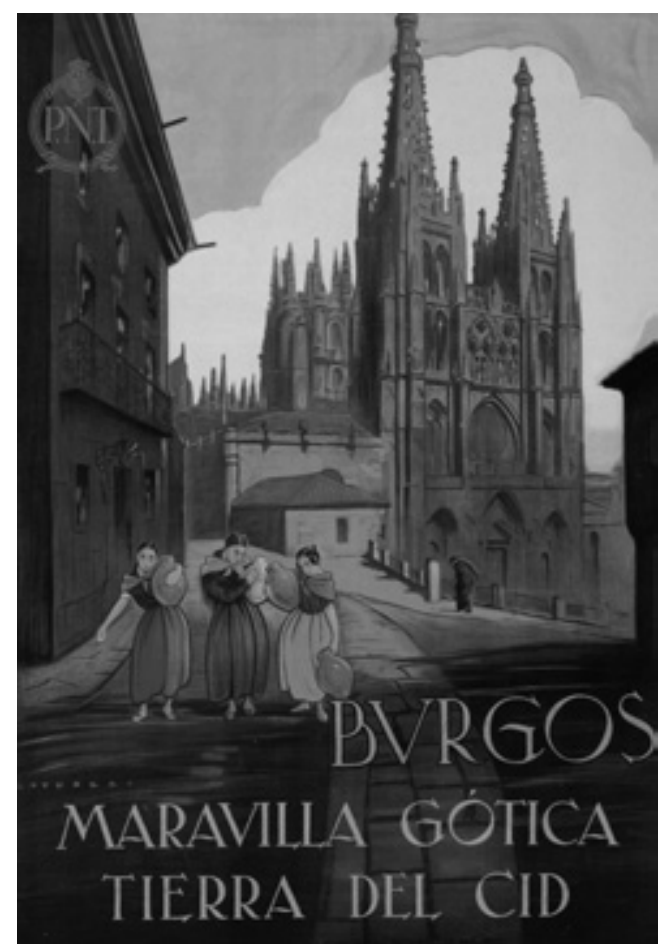

Fig. 7. Loygorri, Burgos. Maravilla Gótica, Cartel, 1929, Patronato Nacional del Turismo. Fondos del Instituto de Estudios Turísticos del Ministerio de Economía y Hacienda.

bajo, credibilidad casi de etnógrafo o folklorista, no es menos cierto que el modo en el cual baraja y organiza el material es una ficción con apariencia de autenticidad en virtud de la propia lógica interna en la narrativa visual que reorganiza en el taller a la hora de ejecutar la obra — de ahí que se haya citado el término de Hannigan.

Se trata, por tanto, de un catálogo de imágenes que pueblan el taller del artista convertido en un único lugar donde el montaje último puede organizar la impresión de verosimilitud. De hecho, aunque parte de la escenografía de este panel concreto - la parte al menos que se distingue de forma más clara- proviene de la

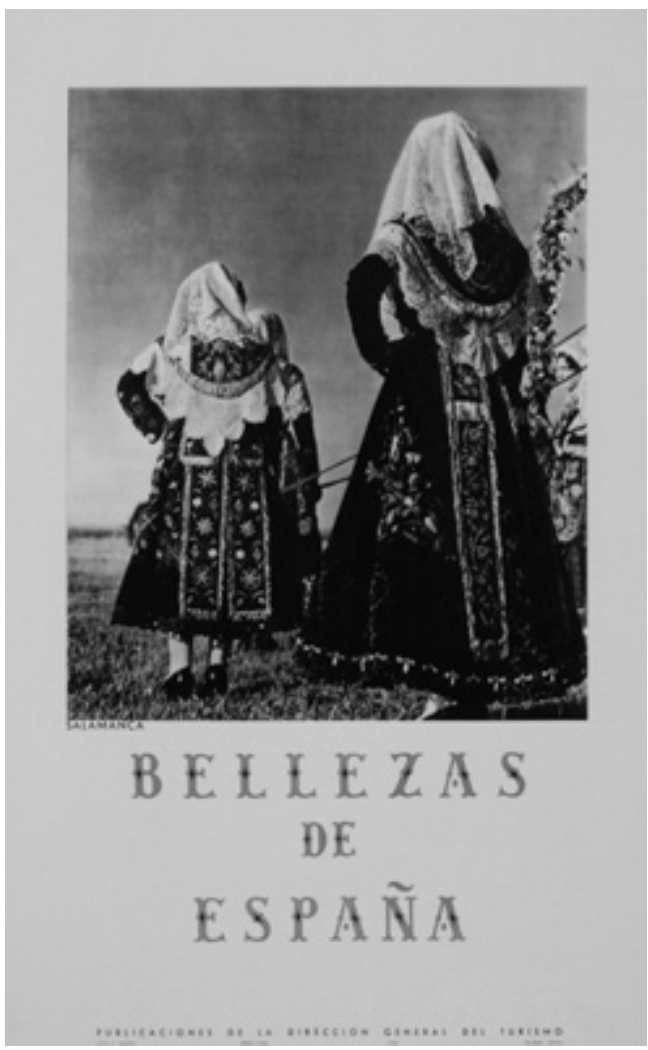

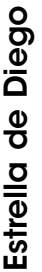

Fig. 8. G. Ubierna, Bellezas de España, Cartel, 1946 (?), Dirección General del Turismo. Fondos del Instituto de Estudios Turísticos del Ministerio de Economía y Hacienda.

abulense Fuente de Pradillo, otros fragmentos arquitectónicos ocupan el telón de fondo para la escena y dan coherencia al texto visual: son las postales turísticas que, igual que ocurre con los trajes y hasta con las ceremonias - los rituales - representadas, testifican el estereotipo del estereotipo: sacar cada cosa de su contexto y resituarla en otro donde la lectura última es más eficaz y donde partes en apariencia discordantes adquieren una unidad artificiosa.

Esa es, precisamente, la idea implícita en el citado término "phantasy cities" —que en este contexto se podría traducir como "ciudades de ficción"- , esas que ahora inundan el globo y no únicamente sobre el papel. John Hannigan 


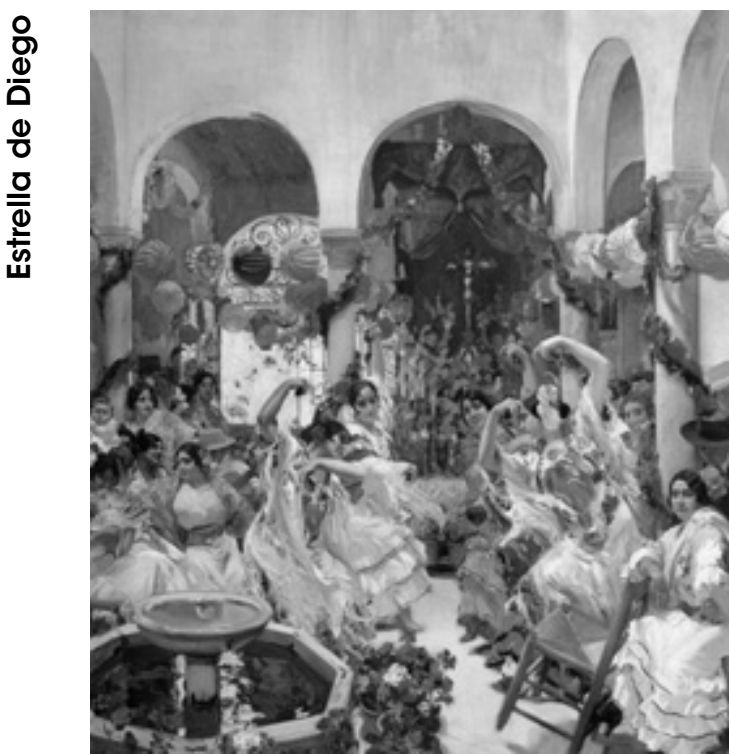

Fig. 9. Joaquín Sorolla, Sevilla. El baile, Visiones de España, 1915.

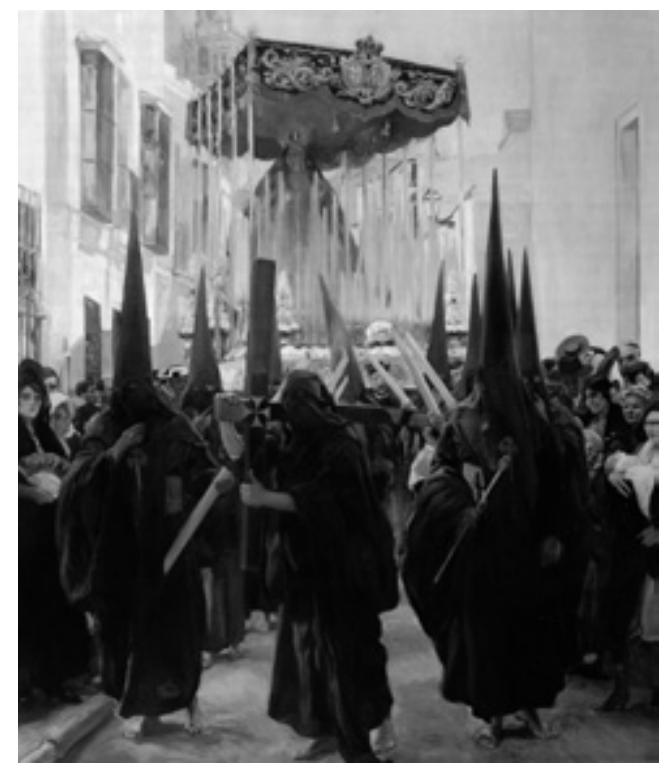

Fig. 10. Joaquín Sorolla, Sevilla. Los Nazarenos, Visiones de España, 1914. ha hablado de estas "ciudades de ficción", típico producto de las sociedades post-industriales, como lugares autosuficientes que por no necesitar, no nos necesitan ni quisiera a nosotros en tanto "nosotros", y las ha definido como esos sitios en los cuales paseando entre su apariencia de calles, mientras dura la experiencia, seremos meros actores.

No en vano y siempre según Hannigan, la "ciudad de ficción" suele estar organizada en base a un orden interno, el de un tema concreto que permite dirigir la esencia última del proyecto: el consumo. El consumo debe entenderse en nuestro contexto, claro, en un sentido más amplio que la mera pasión por la compra: una especie de actitud voraz que inunda todo y se apodera de todo, pues todo va dirigido hacia un fin común -y en el caso de los paneles de la Hispanic Society queda claro en tanto consumo de la imagen de España. Esa "ciudad de ficción" tiene, además, mucho de collage, añade Dear $^{13}$, donde partes sin relación aparente se emparentan y se enredan, una especie de pasti- che de autoabastecimiento que conforma aquello que Soja"14 define como "aglomeración gigante" —de ahí su esencia "posmoderna", por lo que venga tan absurdo término.

Teniendo esto en cuenta puede decirse que la "ciudad de ficción" es, en primer lugar, solipsista, apartada de los vecindarios colindantes o de las ciudades en un caso extremo como Las Vegas, en medio del desierto- "física, económica y culturalmente", aclara Hannigan. Vive, pues, al margen de la pobreza, la injusticia social, la delincuencia... Al margen de la vida real, en pocas palabras. $\mathrm{O}$, dicho de otro modo, de una forma semejante a la cual se presenta la realidad en las guías o lo programas turísticos, en los cuales los falsos se acaban por convertir en auténticos y los auténticos en falsos a partir de una inesperada ars combinatoria.

Esa capacidad de convertir los falsos en auténticos o de resignificar los falsos mismos aparece también en el texto visual de Sorolla, donde lo auténtico y lo falso conforman una unidad ambigua en la cual es la verosimilitud, la 


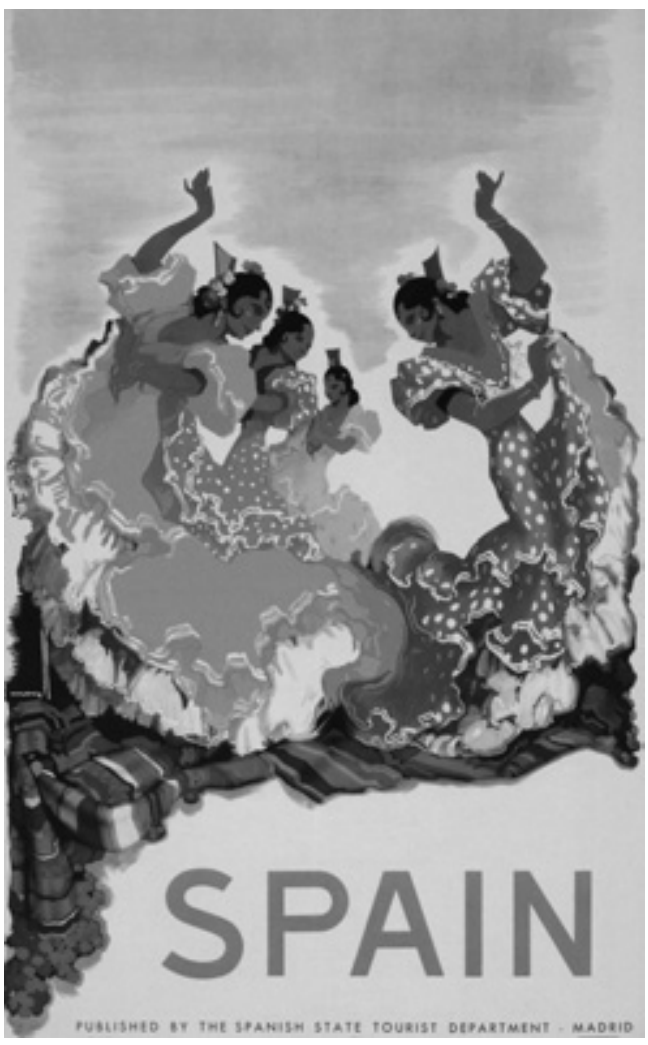

Fig. 11. Morell, España, Cartel, 1941 (¿), Dirección General del Turismo. Fondos del Instituto de Estudios Turísticos del Ministerio de Economía y Hacienda.

unificación textual que se lleva a cabo en el estudio del pintor - la ficción construida sin fisuras en pocas palabras-, la que crea la impresión de "autenticidad" incuestionable. Y se trata, desde luego, de una impresión que no es errónea -o no del todo. La sierra es auténtica y los edificios, así como los trajes y los rituales - o casi. Sólo que en la realidad no se hallan jamás compartiendo el espacio que aquí se les ha asignado.

De esta forma, cada uno de los elementos, reunidos, organiza una ficción que va incluso más allá: la ficción que, a través de los estereotipos que no son sino elementos aislados y re-

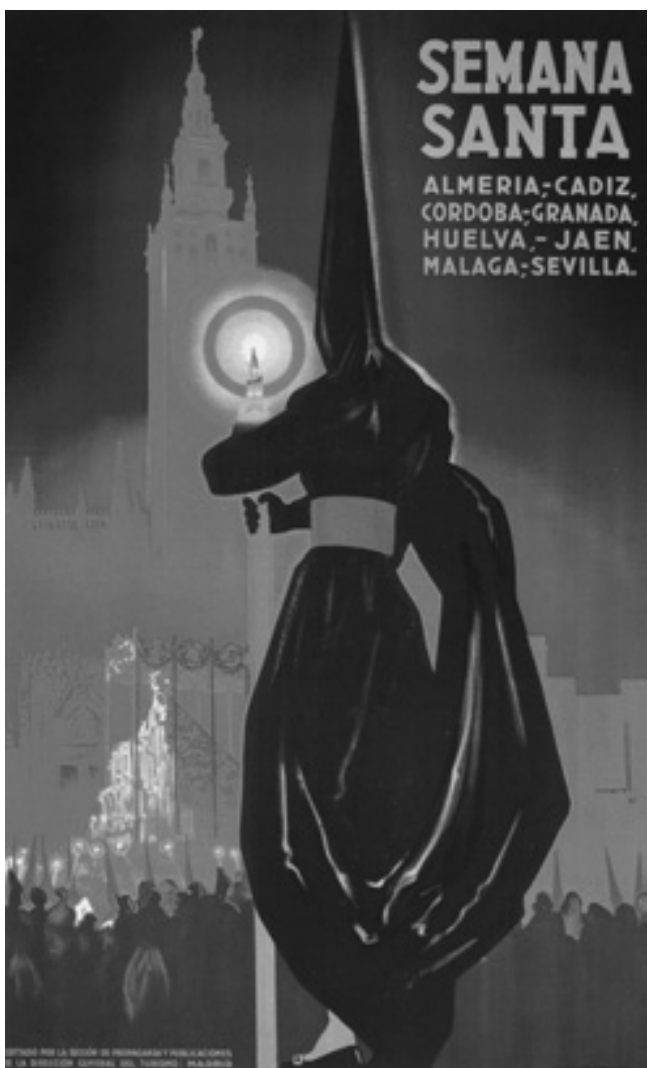

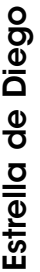

Fig. 12. Morell, Semana Santa, Cartel, 1941, Dirección General del Turismo. Fondos del Instituto de Estudios Turísticos del Ministerio de Economía y Hacienda.

significados, define España como un todo. Cada región termina por ser lo que parece más característico de sus habitantes, con especial énfasis en las costumbres, edificios, fiestas populares, etc, trabajo casi de antropólogo, se advertía, que comienza en el siglo XIX y acaba por ser retomado por la Segunda República primero y hasta el Franquismo después a través de los famosos "coros y danzas".

Con significaciones y estrategias diferentes en cada caso, se busca un resultado al final semejante, pese a todo, a veces desde la "alta cultura" —el trabajo de Sorolla— o desde la "baja cultura" y los productos de consumo — la 


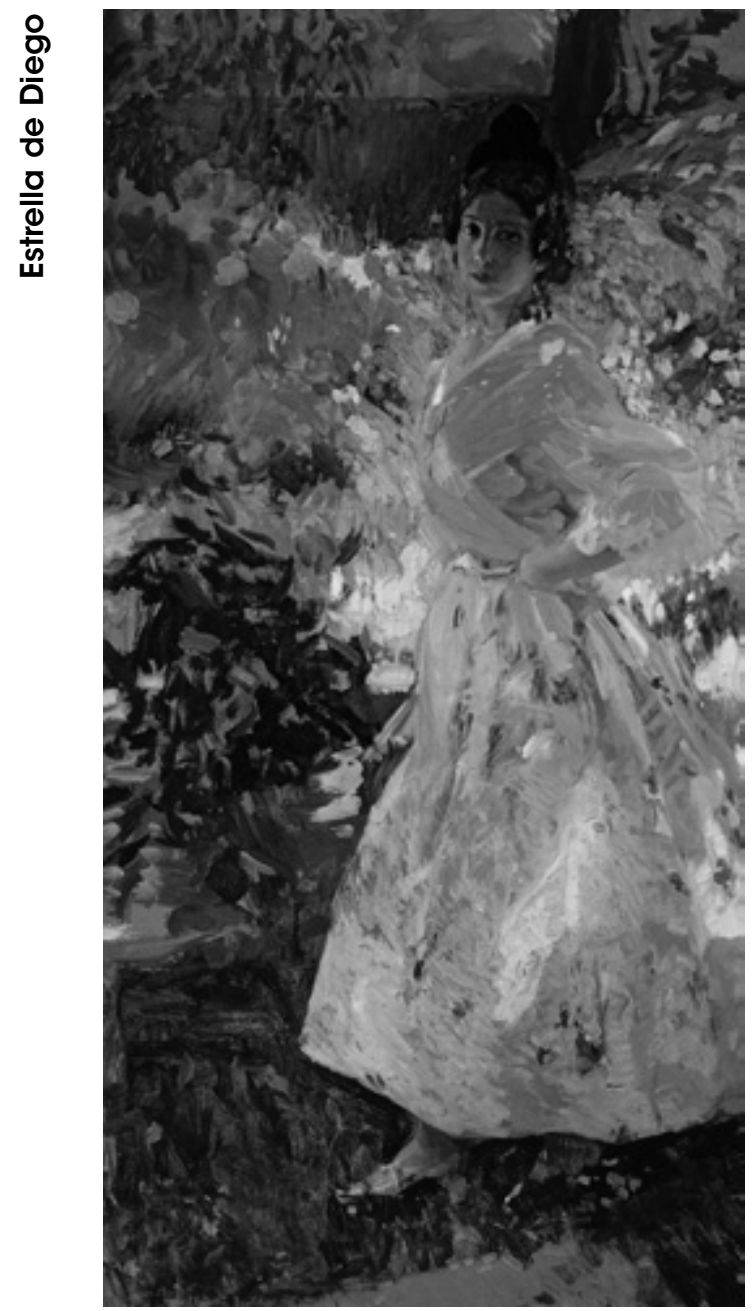

\section{PLAYASDELEVANTE}

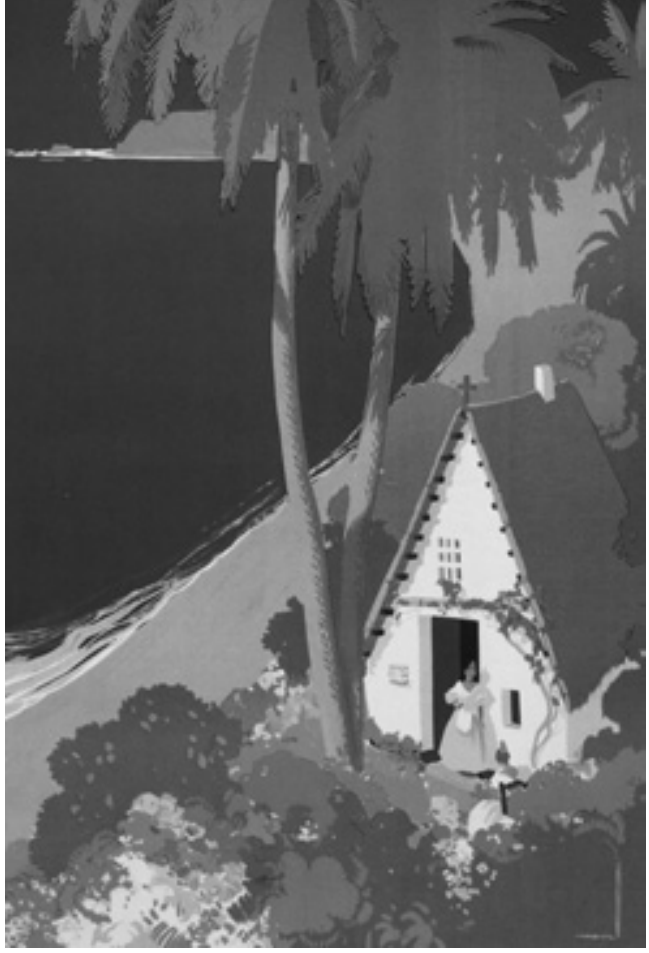

Fig. 14. Morell, Playas de Levante, Cartel, 1941 (i), Dirección General del Turismo. Fondos del Instituto de Estudios Turísticos del Ministerio de Economía y Hacienda.

Fig. 13. Joaquín Sorolla, Valencia. Las grupas, Visiones de España, 1916. 


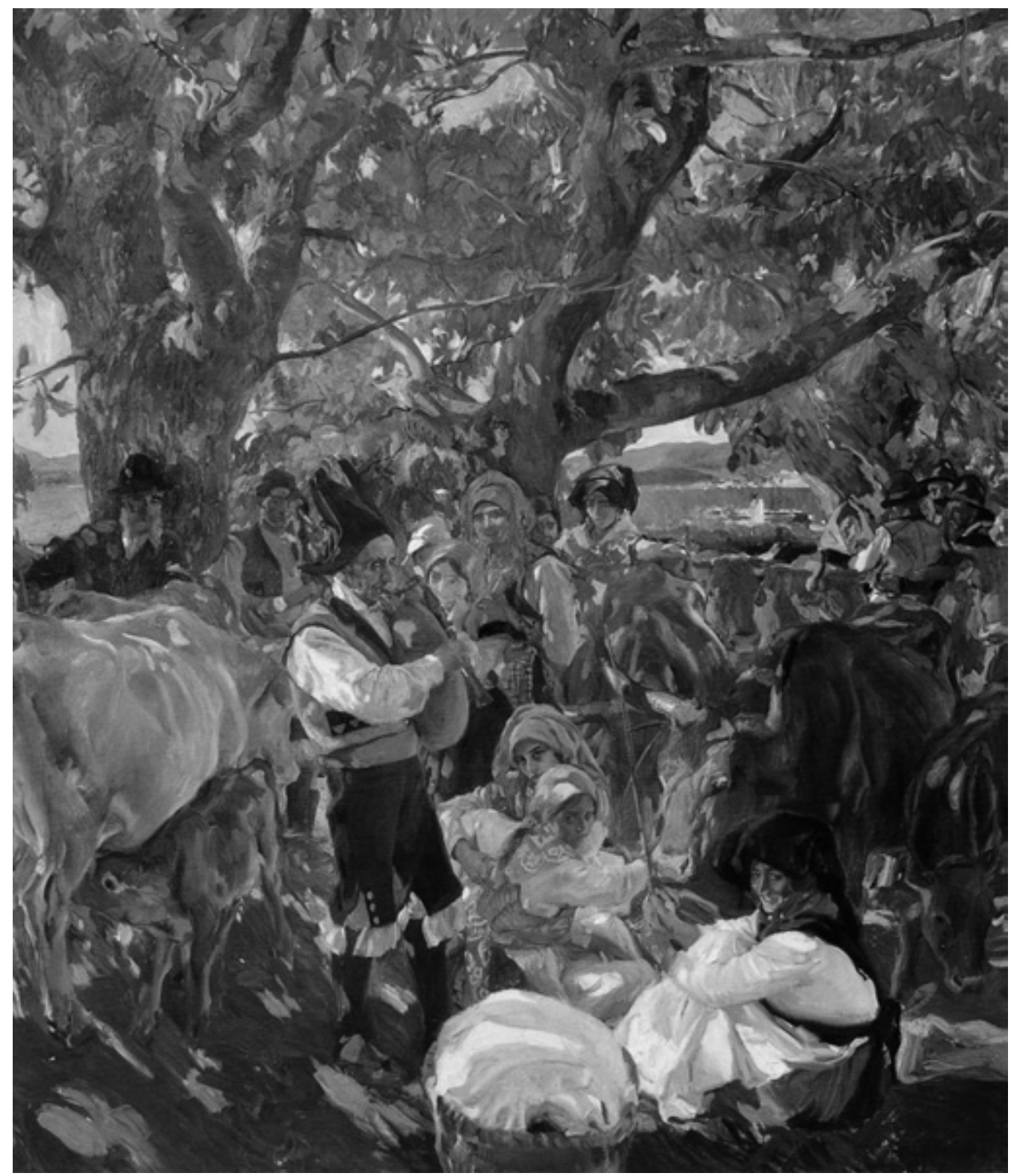

응
$\frac{0}{0}$
$\frac{0}{0}$
$\frac{0}{\overline{0}}$
$\frac{\hbar}{40}$

Fig. 15. Joaquin Sorolla, Galicia. La Romería. Visiones de España, 1915. 
propaganda turística. Basta con mirar los modos de representación de las diferentes regiones en dichas pinturas y el modo de articularlas en las campañas de promoción turística desde finales de los 20 en adelante para observar las similitudes. Quizás en el fondo, los pintores "regionalistas" no son sino los pintores de lo típico, lo "pintoresco", con toda la tradición que arrastran en las construcciones de los estereotipos culturales.

Sobre algunas de estas cuestiones resultan esclarecedoras las reflexiones del reverendo Gilpin de mediados del XVIII en su acepción de lo "pintoresco":

Una obra arquitectónica de Palladio escribe Gilpin - puede ser elegante en grado máximo. (...) pero si la incorporamos a una pintura, inmediatamente pasará a ser un objeto afectado y dejará de agradar. Si deseamos dotarla de belleza pintoresca, deberemos emplear el mazo en lugar del cincel, tendremos que derribar la mitad del edificio, mutilar la otra mitad y tirar los fragmentos amontonados por los alrededores. En resumen, tendremos que convertir un edificio cuidadosamente acabado en una tosca ruina ${ }^{15}$.

Esa noción de "belleza pintoresca" es, de hecho, la que prevalece en esas representaciones, la que nos gobierna, y la que se emparenta con la idea misma de "típico", dado que ese tipo que belleza apela a lo "tosco" frente a lo "liso", diría Gilpin. En pocas palabras, se ajusta a las expectativas del "consumo cultural". Lo pintoresco es cierta puesta en escena de lo "salvaje": lo exótico sin peligros, lo curioso construido; convertir en extraordinario e inesperado algo que de partida no lo era.

Aunque lo malo de la estructura del gusto es su extraordinaria voracidad, la manera en el cual cada cosa, hasta las más inesperadas, puede pasar a configurar el catálogo de lo que "se espera ver". Infinitas propuestas para turistas. Desde ese punto de vista Visión de España de la Hispanic Society, ejecutada entre 19111919, resume muchos de los citados intereses de índole antropológico de la época y que en el caso de Sorolla son anteriores a ese encargo, como muestra la obra de 1907 Aldeanos leoneses. De hecho, parece que fue el artista quien propuso el cambio iconográfico final, más orientado hacia la "etnografía" frente al deseo de Archer Huntington de decorar las paredes con unos lienzos que se centraran en la historia de España.

La idea de esa visión "etnográfica" queda patente en la comentada La fiesta del pan (Fig. 3), donde los trajes, las cerámicas, los monumentos y hasta los paisajes se mezclan como parte del mismo todo, lo "curioso", lo "pintoresco", que también explotan los carteles publicitarios de finales de los 20 del XX, se advertía. De hecho, sólo con repasar la producción del Patronato Nacional de Turismo, germen de la construcción en la imagen de España desde ese momento histórico en adelante, aparecen evidentes puntos de contacto con la iconografía de Sorolla haciendo por tanto pensar en una fuente común y claramente enraizada de la "diferencia" que llega hasta la propaganda para el turismo en tiempos de Franco. También se trastocan muchos de los lugares comunes, como por ejemplo que desde la oficialidad se potencia sólo el turismo de playa o de toreros y bailaoras - muy popular en ambos casos, como es lógico. Parece obvio que a lo largo del tiempo todas las regiones son exhibidas en sus particularidades, a la vez que se trata de ofrecer una visión moderna del país incluso en medio de su "exotismo". Es patente incluso en el citado cartel de 1929, en el cual apoyado en una columna, en medio de las arcadas árabes y la llamativa leyenda "El confort de Europa, la exuberancia de Africa les espera en España", se dibuja un estilizado caballero decó, quien sabe si para probar la primera parte del axioma.

No es el único ejemplo que apela a lo que hoy en día se podría llamar "turismo cultural" con las implicaciones que tiene mostrar la parte "moderna" del país — o visitada por la "modernidad", que eso no queda del todo claro. Un cartel dibujado por Santonja Rosales en 1929 para Francia y donde se anuncia el Museo de Escultura policromada de Valladolid, muestra a una pareja "moderna" de turistas admirando, guía en mano para informarse con más precisión, y una obra de arte —de apariencia "moderna" 


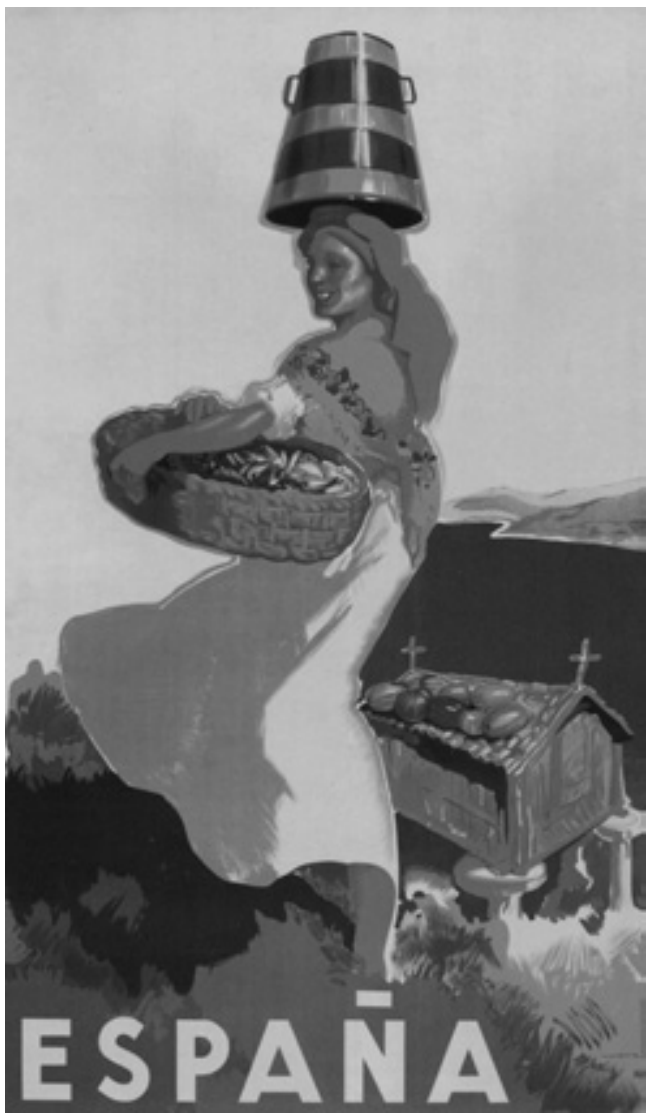

Fig. 16. Morell, España, Cartel, 1940, Dirección General de Turismo. Fondos del Instituto de Estudios Turísticos del Ministerio de Economía y Hacienda.

también (Fig. 4). Un año más tarde otro dibujo de Roberto Domingo publicita el Parador de Gredos - para uso nacional- y en él se muestra un animado grupo "moderno" y un coche azul al fondo, al lado de lo que se podría leer como "locales" con caballos, dispuestos a pasear a los excursionistas pertrechados, como el caballero de la derecha, de sus artefactos para caminata campo a través (Fig. 5). Esa misma idea de mezclar el monumento - la tradición-con los turistas, incluso venidos de lugares más "modernos" que la propia España y por lo tanto con ropas más atrevidas que las corrientes en la España de la época, aparece en 1966, desde el entonces Ministerio de Información y Turismo, en un cartel fotográfico de Josip Ciganivic —a menudo se contrataba a fotógrafos de gran calidad para realizar las campañas- donde se muestra el interior de la Mezquita lleno de turistas distinguidos (Fig. 6).

Pero volviendo a La fiesta del pan, es curioso notar cómo esa misma pasión etnográfica querer mostrar a las gentes y las costumbres y rituales de las gentes que aparece de forma clara en la producción de Ortiz Echague- se retoma en algunos carteles posteriores. En un cartel de Burgos de uso interno - "Burgos. Maravilla gótica. Tierra del Cid" - que Loygorri realiza en 1929 para el Patronato Nacional de Turismo, se repite el esquema: delante de la majestuosa catedral al fondo, tres mujeres vestidas con trajes populares sostienen unos cántaros de cerámica en la mano (Fig. 7). Se trata de una puesta en escena que vuelve a aparecer en la campaña de mediados de los 40 de la Dirección General de Turismo, cuyo nombre para el uso local, Bellezas de España —en la campaña de Francia se traduce como "Visitez l'Espagne" y en la inglesa "Spain: Every Type of Art. Every Phase of Nature", era habitual usar las mismas imágenes con distinto eslogan dependiendo del país-, es bastante elocuente. En la serie, entre cuyos fotógrafos se halla el propio Ortiz Echague, se alternan paisajes, monumentos y trajes regionales (Fig. 8), los elementos que Sorolla reúne en su collage y que conviven en Visiones de España.

Esas mismas afinidades las encontramos en la representación de otras regiones. A veces en el caso de un área como Sevilla, típica y "pintoresca" por antonomasia, aunque también en otras menos explotadas popularmente como Galicia. En el primero, las afinidades de los paneles Sevilla. El baile (1915) (Fig. 9) y Sevilla. Los Nazarenos (1914) (Fig. 10) con sendos carteles de 1941 para la Dirección General de Turismo, son obvias: en uno se representan unas bailaoras (Fig. 11) y en el otro un encapuchado y la catedral al fondo, anuncio de la Semana Santa (Fig. 12).

En el caso de otras regiones menos explotadas turísticamente también se encuentran puntos de 
contacto. Tal ese el caso de Valencia: Valencia. Las grupas (1916) (Fig. 13) de Sorolla tiene su correlato en un cartel de la misma serie de Morell de 1941 donde se muestran algunos de los mismos estereotipos: naturaleza rica, una mujer ataviada con el traje regional y, como suele ser recurrente en esta serie, una casa típica de la región en ese despliegue etnográfico que por motivos obvios es acogido con entusiasmo durante el franquismo (Fig. 14). Un patrón similar se repite para Galicia: si en el anuncio de la misma serie, en este caso en un trabajo de 1940, aparece una mujer con ropa campesina portando el característico cántaro en la cabeza y al fondo se ve un hórreo y el mar azul (Fig. 15) poniendo en evidencia el predominio de la zona rural y el paisaje de la región, en Galicia. La Romería (1915) de Sorolla se vuele a enfatizar lo popular y lo bello de la naturaleza (Fig. 16).

¿Era ésa la realidad, las realidades, de España? ¿Es esa o sólo esa la España que recogen los carteles y la publicidad turística muy diversificada por zonas, como se anunciaba, tratando de poner en evidencia lo turístico, en el fondo lo "pintoresco" de cada una de ellas? Aunque más aún. Quién sabe si lo que llamamos la realidad es, sencillamente, otro modo de representarse, un relato bien construido.

Sin embargo, Sorolla no estaba solo, claro, en su construcción de la España "pintoresca" y, por tanto, exótica y exportable. Mongrell, López Mezquita y hasta el mismo Pinazo - todos ellos estudiados a fondo por Javier Pérez Rojas ${ }^{16}$ por citar otros autores de su misma área de procedencia-, retoman las imágenes de Valencia y de otras partes de España en el caso del último, quien también trabaja para la Hispanic Society. Es la idea de producir para el exterior, idea esencial en la construcción de estereotipos culturales que reenvían también a ciertas puestas en escena del mencionado exotismo.

Sea como fuere muchos de estos estereotipos culturales van pasando a las prácticas culturales franquistas, como se anunciaba, y sus exportaciones no sólo de imágenes, sino de artistas. Así, en la exposición oficial de arte español de El Cairo de $1950^{17}$ comisariada por Enrique Pérez Comendador, con la asistencia del pintor
Joaquín Valverde, se organizan y apuntalan algunos de los estereotipos de los cuales hemos ido hablando y que van a gobernar la confomación de "lo español" que termina por ser un lugar común en la historias de representación de España en las exposiciones internacionales.

Es obvio que hay una figura de héroe $-\mathrm{y}$ creo que esto no ha sido aún superado-, Goya - igual que ocurrió en la reciente exposición del Reina Sofía en la cual es enfrentado El Guernica con Los fusilamientos-, que dos años después, en Venecia, vuelve a aparecer como iniciador de la joven generación y contrapuesto a Saura, quien a su vez remacha la ficción siguiendo/pintando a lo Goya. La idea es describir la pintura española "de Goya a nuestros días", como si el siglo XIX fuera un mal sueño que hay que olvidar. Me pregunto si eso explicaría la escasa fortuna crítica de nuestro XIX entre nosotros hasta época reciente.

Sea como fuere, por primera vez en El Cairo se expuso a Picasso y a Dalí y se llevaron artistas ligados al Regionalismo. Solana, el gran héroe de la construcción de "lo español" era pronto apoyado por Sorolla que entra como parte de cierto aire modernizador que, tratando de huir de la España "negra" y mostrar esa España luminosa que muestran los carteles, acaba por expulsar a Solana en favor de Anglada Camarasa. Parece, pues, esencial desentrañar el papel de cada uno de los pintores de lo "pintoresco" o, sencillamente, típico, entre los cuales estaría en este contexto al menos Sorolla, y tratar de dilucidar por qué unos optan por símbolos de la supuesta modernidad y otro no.

Dos preguntas resultan al final inevitables: qué entendían algunos por "España" y qué era España en "realidad", si fuera posible hablar de "realidad" en cuestiones relacionadas con las identidades nacionales, construcciones cada una. Tal vez, lo que distinguiría a una comunidad cultural de otra sería su forma de organizar la narrativa: las comunidades no se pueden distinguir por su falsedad/genuinidad, sino por el estilo en que son imaginadas, diría Anderson, de ahí la importancia de estas imágenes que parecen pasar de una época a otra, de la alta a la baja cultura como fórmula de reconocimiento. 
NOTAS

${ }^{1}$ La investigación para este trabajo se ha llevado a cabo dentro del proyecto de investigación "Los lugares del Arte. Del taller del artista al espacio expandido en la sala de exposición". Referencia HAR2010-19406 (Ministerio de Ciencia e Innovación).

2 G. Apollinaire, Los pintores cubistas, La Balsa de la Medusa, Madrid 1994, p. 40.

${ }^{3}$ G. Stein, Picasso, Biblioteca La Esfera, Madrid, 2002, p. 81.

${ }^{4}$ A. Breton, Los pasos perdidos, Alianza Editorial, Madrid, 1972, p.136.

${ }^{5}$ E. de Amicis, España. Diario de viaje de un turista escritor, Madrid, 2000, p. 227.

${ }^{6}$ A. Dumas, De París a Cádiz, Madrid, 1992, p. 94.

${ }^{7}$ E. Said, Orientalismo, Madrid, 2002.

8 L. Andreas-Salomé, Mirada retrospectiva, Madrid, 1980, p.63.

${ }^{9}$ G. Stein, Op. Cit., p. 82.
${ }^{10}$ Idem, p.39.

${ }^{11}$ La bibliografía sobre Sorolla es tan extensa que nos limitaremos a citar la ultima exposición del Museo de Prado donde se presentaron los paneles y en cuyo catálogo se recoge de de forma exhaustiva la bibliografía sobre el tema. La muestra fue comisariada por José Luis Díez y Javier Barón: Joaquín Sorolla, Museo Nacional del Prado, 2009. Otra referencia sobre este tema concreto es la comisariada por Felipe Garín y Facundo Tomás: Sorolla .Visión de España. Colección de la Hispanich Society of America, Valencia, Banjaca, 2007, por citar la última muestra de las numerosas que se han hecho sobre el pintor valenciano.

12 J. Hanningan, Fantasy City. Pleasure and Profit in the Postmodern Metropolis, Routledge, Londres y Nueva York, 2006.

${ }^{13}$ Dear, M., "Prolegomena to a Postmodern Urbanism", Managing Cities: The New Urban Context, Chichester (West Sussex), 1995.
14 Soja, E., Postmodern Geographies, Nueva York, 1989.

${ }^{15}$ W. Gilpin, Tres ensayos sobre la belleza pintoresca (ed. J. Maderuelo), Abada, Madrid, 2004, p.60.

${ }^{16}$ Sobre López Mesquita y Pinazo ver: Javier Pérez Segura, López Mezquita. Épocas e itinerarios de un pintor cosmopolita. De Granada a Nueva York. Arcolibros, Madrid, 2007 (pp. 25-431). Ignacio Pinazo, 1849-1916. Los inicios de la pintura moderna. Fundación Cultural Mapfre Vida, 2005 (pp. 25-431). Ignacio Pinazo. El humo del amor, IVAM, Valencia, 2011. Para Mongrell ver José Luis Alcaide José Mongrell Torrent (1870-1937). Valencia, Generalitat Valenciana, 2001, pp. 275- 357.

17 Sobre esta cuestión se puede consultar el trabajo inédito de $\mathrm{A}$. Fuentes Vega, "El Cairo, 1950", en Exportación cultural española 19471952. El papel de los artistas españoles en la proyección de la identidad nacional. Trabajo de investigación DEA (inédito), Madrid, 2009 (pp. 70-100). 